mother ; not only is she denied the immediate joy of seeing and holding her newborn child but she has to face the next few days in doubt and uncertainty, at a time when she should be receiving the reward for months of discipline and weeks of separation from her family. Tact, sympathy, and encouragement are needed at this stage, and the obstetrician should see to it that the patient receives adequate preparation for this final period of waiting in the weeks before delivery.

\section{Summary}

The 113 pregnancies (115 foetuses) occurring in 80 diabetic patients treated in the Royal Maternity Hospital, Belfast, over the eight years 1956 to 1963 have been reviewed.

The total foetal loss was $16.2 \%$ and the perinatal mortality $11.9 \%$. Although these results are an improvement on those of the previous years they are still too high.

The management of these diabetic patients over the past eight years is discussed and those factors considered mainly responsible for the reduction in perinatal mortality are emphasized.

Certain alterations in our present management have been made in the hope that our present foetal loss can be reduced still further. The most important of these are: (1) a special antenatal clinic for diabetic patients attended by both physician and obstetrician ; (2) strict antenatal supervision from the early weeks in an attempt to reduce the number of miscarriages; (3) rigorous control of the diabetes and the use of a twice-daily insulin dosage regime; (4) admission to hospital at least four weeks before the provisional date of delivery and not later than 32 weeks ; (5) the maturity at which delivery should take place must be carefully selected for each individual patient-routine delivery at a particular maturity must be abandoned ; (6) unless there is some contraindication, a trial medical and/or surgical induction of labour with certain reservations should be attempted in primigravid as it is in the multigravid patients.
We wish to thank Professor C. H. G. Macafee and the consultants of the Royal Maternity Hospital, Belfast, for permission to study the obstetric records of these patients. We are indebted to Professor Macafee-who was responsible for the obstetric management of these patients-for his advice and encouragement in writing this paper. The assistance of the tutors and resident medical staff in the management of these patients was invaluable, and to them we are most grateful. We would also like to thank Professor F. M. B. Allen, the consultant paediatricians, and the nursing staff of the premature nursery unit of the Royal Maternity Hospital, without whose skilled care and attention many of the babies might not have survived. Our thanks are also due to Dr. J. A. Weaver and the registrars and senior house officers of the metabolic unit of the Royal Victoria Hospital, who assisted us in the diabetic management of these patients. We also wish to thank Professor E. A. Cheeseman, of the Department of Social and Preventive Medicine, the Queen's University of Belfast, for statistical help; and Miss $M$. Weller for secretarial assistance.

\section{REFERENCES}

Barns, H. H. F., and Morgans, M. E. (1948). F. Obstet. Gynaec. Brit. Emp., 55, 449.

Claye, A. M., and Craig, W. S. (1959). Arch. Dis. Childh., 34, 312.

Clayton, S. G. (1956). F. Obstet. Gynaec. Brit. Emp., 63, 532. Crenshaw, C., Parker, R. T., and Carter, B. (1962). Obstet. and Gynec.,
20, 334.

Dolger, H., Bookman, J. J., and Nechemias, C. (1963). F. Mt Sinat Hosp., 30, 479.

Drury, M. I. (1961). Irish f. med. Sci., 430, 425.

Louw, J. T., and Sinclair, R.St.C. (1957). S. Afr. med. 7., 31, 28.

Parkin, G. M. (1958). Med. 7. Aust., 1, 622.

Pedersen, J., and Branstrup, E. (1956). Lancet, 1, 607.

Peel, J. H. (1955). Brit. med. F., 2, 870.

- (1962). Amer. F. Obstet. Gynec., 83, 847

Stevenson, A. E. M. (1956). Brit. med. f., 2, 1514.

von Schubert, E. (1960). Geburtsh. u. Frauenheilk., 20, 1029.

White, P. (1949). Amer. F. Med., 7, 609.

(1959). In Treatment of Diabetes Mellitus, edited by E. P. Joslin,
H. F. Root, P. White, and A. Marble, 10th ed. Kimpton, London.

Wilson, R. B., and Morrison, M. G. (1962). Clin. Obstet. Gynec., 5, 419.

\title{
Epilepsy after Ruptured Intracranial Aneurysm
}

\author{
F. CLIFFORD ROSE,* M.B., M.R.C.P. ; MARTIN SARNER, † M.B., M.R.C.P.
}

Brit. med. F., 1965, 1, 18-21

The association of epilepsy with cerebrovascular disease is well recognized, but the frequency with which fits follow a proved ruptured intracranial aneurysm is unknown. In order to ascertain the incidence of epilepsy subsequent to subarachnoid haemorrhage from an intracranial aneurysm a retrospective survey has been done on an unselected group of proved cases and a sample of these personally seen and analysed.

\section{Case Material}

The patients in this series were all those admitted to Atkinson Morley's Hospital during the five-year period 1958-62. Subarachnoid haemorrhage was confirmed in every case by lumbar puncture and the presence of one or more aneurysms proved

- Consultant
Lambeth Hourologist, Royal Eye Medical Ophthalmology Unit, Lambeth Hospital, London ; First Assid

t Research Assistant, Department of Neurosurgery, Atkinson Morley's (St. George's) Hospital, London. by arteriography. Epilepsy is here defined as one or more fits, of any type, occurring at any time after the haemorrhage; there was no case with a history of fits before the bleed. The term "survivor" is applied to those patients who have survived for six months or longer from the time of the bleed.

The series totalled 1,009 cases and there was an excess of females in the proportion of $3: 2$. There were 508 survivors, and of these $53(10.4 \%)$ developed epilepsy (Table I). Since the figure of $10.4 \%$ was derived from case records only, it was decided to examine a sample of the series at a follow-up clinic ; these were the survivors from the 137 cases of ruptured intracranial aneurysm admitted to the neurosurgical unit between 1 July and 31 December 1960 . Of the 63 survivors, 61 attended for the follow-up examination, at which a family and past medical history was again taken, with particular reference to epilepsy. Fits of varying types were found to have occurred in nine cases $(14.8 \%)$. This is four more than expected from the case record survey, which was approximately 10 cases per annum, and indicates that the incidence of epilepsy is prob- 
ably of the order of $15 \%$ of survivors (Table II). Even if the lower estimate is taken, it is still 20 times greater than the incidence in the general population (approximately $0.5 \%$ ).

TABLE I.-Ruptured Intracranial Aneurysm. 1958-62

\begin{tabular}{|c|c|c|c|c|c|}
\hline & & & Male & Female & Total \\
\hline $\begin{array}{l}\text { No. of cases } \\
\begin{array}{l}\text { Survivors } \\
\text { Post-ictal epilepsy }\end{array} \\
\text { No epilepsy }\end{array}$ & $\begin{array}{l}\because \\
\because \\
.\end{array}$ & $\begin{array}{ll} & \\
\because & \\
\because & \\
. & \end{array}$ & $\begin{array}{l}383 \\
208 \\
17 \\
191\end{array}$ & $\begin{array}{r}626 \\
300 \\
36 \\
264\end{array}$ & $\begin{array}{r}1,009 \\
508 \\
53 \\
455\end{array}$ \\
\hline
\end{tabular}

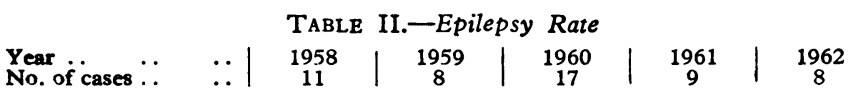

\section{Factors Influencing the Frequency of Epilepsy}

1. Age of Patient (Table III).-The percentage surviving decreases in each successive decade. The epilepsy rate for the sixth and seventh decades, which contain most of the survivors, is $6.4 \%$, whereas the comparable figure for the third to the fifth decades is $15.8 \%$. Epilepsy is therefore more likely to occur in the younger age-groups $(\mathrm{P}<0.01)$.

\begin{tabular}{|c|c|c|c|c|c|c|c|c|}
\hline & & $<20$ & $20-29$ & $30-39$ & $40-49$ & $50-59$ & $60-69$ & $70+$ \\
\hline 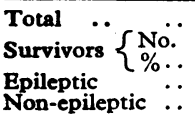 & $\begin{array}{l}\ldots \\
\because \\
\cdots \\
.\end{array}$ & $\begin{array}{r}15 \\
12 \\
80 \\
0 \\
12\end{array}$ & $\begin{array}{l}43 \\
28 \\
65 \\
4 \\
24\end{array}$ & $\begin{array}{r}121 \\
68 \\
56 \\
9 \\
59\end{array}$ & $\begin{array}{r}244 \\
125 \\
51 \\
22 \\
103\end{array}$ & \begin{tabular}{|r|}
325 \\
164 \\
50 \\
11 \\
153
\end{tabular} & $\begin{array}{r}232 \\
101 \\
44 \\
6 \\
95\end{array}$ & $\begin{array}{r}29 \\
10 \\
34 \\
1 \\
9\end{array}$ \\
\hline
\end{tabular}

2. Site of Aneurysm (Table IV).-Although a large number of the aneurysms in this series arise from the anterior cerebral and anterior communicating artery complex, of the 135 survivors in this group only $3(2.5 \%)$ developed epilepsy. Of those who survived with a middle cerebral artery aneurysm, $30(25 \%)$ have developed fits. The figure for the posterior communicating aneurysm group is intermediate-about $9 \%$. Of the six patients who had more than one aneurysm and who subsequently developed epilepsy, three bled from a middle cerebral aneurysm proved at uperation, thus further increasing the number of epileptics in the middle

TABLE IV.- Site of Aneurysm

\begin{tabular}{ll|c|c|c|c|c}
\hline Aneurysm Site & $\begin{array}{c}\text { Anterior } \\
\text { Group }\end{array}$ & $\begin{array}{c}\text { Middle } \\
\text { Crebral } \\
\text { Group }\end{array}$ & $\begin{array}{c}\text { Posterior } \\
\text { Group }\end{array}$ & Other & Multiple \\
\hline Total $\ldots$ & $\cdots$ & 328 & 228 & 211 & 78 & 164 \\
Survivors & $\because$. & 135 & 120 & 133 & 47 & 73 \\
Epileptic & $\because$. & 3 & 30 & 12 & 2 & 6 \\
Non-epileptic & $\cdots$ & 132 & 90 & 121 & 45 & 67 \\
\hline
\end{tabular}

crebral aneurysm group. From these figures it is evident that patients with a ruptured middle cerebral artery aneurysm are particularly at risk with regard to epilepsy $(P<0.001)$. 'The increased risk could be explained on the basis of age-group rather than aneurysm site if the patients with a middle cerebral aneurysm were younger as a group than patients who had an aneurysm elsewhere. Because of this possibility the cases have been arranged by site of aneurysm and by decade (Table $V$ ). Apart from a larger number of patients with an anterior cerebral and anterior communicating aneurysm in the sixth decade, the three groups are not essentially dissimilar. There is, however,

TABLE V.-Cases by Site of Aneurysm and Decade

\begin{tabular}{|c|c|c|c|c|c|c|c|}
\hline Site of Aneurysm & $<20$ & $20-29$ & $30-39$ & $40-49$ & $50-59$ & $60-69$ & $70+$ \\
\hline $\begin{array}{l}\text { Anterior group } \\
\text { Middle cerebral }\end{array}$ & $7(3)$ & $16(8)$ & $44(18)$ & $72(38)$ & $108(61)$ & $73(55)$ & $8(6)$ \\
\hline $\begin{array}{l}\text { group } \\
\text { Posterior group } . .\end{array}$ & $\begin{array}{l}2(1) \\
2(1)\end{array}$ & $\begin{array}{l}9(3) \\
9(1)\end{array}$ & $24(10)$ & $\begin{array}{l}73(28) \\
50(24)\end{array}$ & $\begin{array}{l}66(35) \\
68(22)\end{array}$ & $\begin{array}{l}51(24) \\
51(23)\end{array}$ & $\begin{array}{l}3(3) \\
9(3)\end{array}$ \\
\hline
\end{tabular}

Figures in parentheses indicate number of deaths. a small increase in the number of younger patients in the middle cerebral aneurysm group, but it is probable that both age and aneurysm site are of importance with regard to the development of epilepsy.

3. Epilepsy at Time of Onset of the Bleed (Table VI).-The chances of epilepsy developing after an intracranial aneurysm has ruptured are not greater if a fit occurs at the time of the haemorrhage.

TABLE VI.-Epilepsy at Onset

\begin{tabular}{lll|c|c|c|c}
\hline & & $\begin{array}{c}\text { Anterior } \\
\text { Group }\end{array}$ & $\begin{array}{c}\text { Middle } \\
\text { Cerebral } \\
\text { Group }\end{array}$ & $\begin{array}{c}\text { Other } \\
\text { Aneurysms }\end{array}$ & Total \\
\hline Convulsive onset & $\ldots$ & $\ldots$ & 39 & 24 & 42 & $105 / 1,009$ \\
Survivors $\ldots$ & $\cdots$ & $\cdots$ & 15 & 18 & 15 & $48 / 508$ \\
Epileptics $a$ & $\cdots$ & $\cdots$ & 15 & 13 & 14 & $6 / 53$ \\
Non-epileptics & $\cdots$ & $\cdots$ & 15 & $\mathbf{4 2 / 4 5 5}$ \\
\hline
\end{tabular}

4. Coma at Time of Onset of the Bleed (Table VII).-Of the group of survivors who had a coma producing subarachnoid haemorrhage, $10 \%$ developed epilepsy. This percentage is much the same as that for the series as a whole: no conclusion on the likelihood of subsequent epilepsy can be adduced from the presence of coma at onset.

TABLE VII.-Coma at Onset

\begin{tabular}{|c|c|c|c|c|}
\hline & $\begin{array}{l}\text { Anterior } \\
\text { Group }\end{array}$ & $\begin{array}{l}\text { Middle } \\
\text { Cerebral } \\
\text { Group }\end{array}$ & $\begin{array}{c}\text { Other } \\
\text { Aneurysms }\end{array}$ & Total \\
\hline \begin{tabular}{lll} 
Coma-producing & \multicolumn{2}{c}{ haemor- } \\
rhage.. & $\ldots$ & $\ldots$ \\
Survivors.. & $\ldots$ & $\ldots$ \\
Epileptics & $\ldots$ & $\ldots$ \\
Non-epileptics & $\ldots$ & $\ldots$
\end{tabular} & $\begin{array}{r}124 \\
62 \\
1 \\
61\end{array}$ & $\begin{array}{l}92 \\
52 \\
16 \\
36\end{array}$ & $\begin{array}{r}179 \\
92 \\
5 \\
87\end{array}$ & $\begin{array}{l}395 / 1,009 \\
206 / 508 \\
22 / 53 \\
184 / 455\end{array}$ \\
\hline
\end{tabular}

5. Intracerebral Haematoma or Vascular Spasm.-There were 346 cases showing angiographic evidence of intracerebral haematoma, vascular spasm, or both. Of these, 144 survived and $31(20 \%)$ developed epilepsy, indicating that the presence of haematoma, with or without vascular spasm, predisposes to subsequent fits. Since a ruptured middle cerebral artery aneurysm is more likely to give rise to an intracerebral haematoma than a ruptured aneurysm at another site, both of these lesions together in the same patient-namely, middle cerebral aneurysm and haematoma-constitute a potent epileptogenic focus (Table VIII). Of 158 patients shown to have a middle cerebral aneurysm associated with a haematoma in the temporal lobe or the sylvian fissure, 84 survived for six months or more and $25(30 \%)$ developed epilepsy.

\begin{tabular}{|c|c|c|c|c|}
\hline & $\begin{array}{c}\text { Middle } \\
\text { Cerebral } \\
\text { Aneurysm }\end{array}$ & Others & Total & \\
\hline $\begin{array}{l}\text { Haematoma } \ldots \\
\text { Not haematoma } . .\end{array}$ & $\begin{array}{r}158 \\
70\end{array}$ & $\begin{array}{l}188 \\
593\end{array}$ & $\begin{array}{l}346 \\
663\end{array}$ & $\begin{array}{l}\chi^{2}=158.203 \\
\mathbf{P}<0.001\end{array}$ \\
\hline Total & 228 & 781 & 1,009 & \\
\hline
\end{tabular}

6. Treatment of the Aneurysm (Table IX).-Standard methods of treatment were used as laid down elsewhere (McKissock et al., 1960). In order to determine whether the method of treatment is of significance in the development of epilepsy, two clinically comparable groups of patients, each having a middle cerebral aneurysm but treated at random by bed rest or craniotomy, are compared. Of the eight epileptics who were treated surgically, five had the aneurysm wrapped

\begin{tabular}{|c|c|c|c|c|}
\hline & & Conservative & Craniotomy & Total \\
\hline $\begin{array}{ll}\text { Total cases } & \ldots \\
\text { Survivors } & \ldots \\
\text { Epileptics } & \ldots \\
\text { Non-epileptics } & .\end{array}$ & $\begin{array}{ll}. & \\
\cdots & \cdots \\
\cdots & \cdots\end{array}$ & $\begin{array}{r}55 \\
37 \\
8 \\
29\end{array}$ & $\begin{array}{r}52 \\
40 \\
7 \\
33\end{array}$ & $\begin{array}{r}107 \\
77 \\
15 \\
62\end{array}$ \\
\hline
\end{tabular}


in gauze and in three the aneurysm was clipped at its neck. The numbers are very small, but no significant difference has emerged $\left(\chi^{2}=0.028\right)$.

7. Residual Physical Signs in Central Nervous System (C.N.S.) (Table X).--Residual physical signs in the C.N.S. were analysed only in the sample of survivors seen personally. The signs were usually of a hemiparesis, either motor or sensory, or hemianopia, but an isolated ocular palsy was not assessed as indicating residual brain damage. Seven of the 17 patients with neurological deficit developed epilepsy, as compared with 2 of the 44 without signs. This confirms the expectation that patients with residual brain damage are much more likely to develop fits.

\begin{tabular}{|c|c|c|c|c|}
\hline & & Residual Signs & No Signs & Total \\
\hline $\begin{array}{l}\text { Epileptics } \\
\text { Non-epileptics }\end{array}$ & $\begin{array}{ll}. & . \\
. & .\end{array}$ & $\begin{array}{r}7 \\
10\end{array}$ & 42 & $\begin{array}{r}9 \\
52\end{array}$ \\
\hline
\end{tabular}

\section{Character of the Epilepsy}

1. Time of Onset (Table XI).-The first fit occurred within 18 months of the haemorrhage in 48 of the 53 epileptics. Three patients had their first fit two years or more after the bleed.

TABLE XI.-Time of Onset of the First Fit
\begin{tabular}{c|c|c|c|c}
\hline Within 6 months & $6-12$ months & $12-18$ months & $18-24$ months & 2 years + \\
\hline 18 & 20 & 10 & 2 & 3 \\
\hline
\end{tabular}

2. Type of Fit (Table XII).-The fits were usually generalized, but focal or temporal-lobe attacks or a combination of these occurred. There was no relation between the type of fit and the site of the aneurysm.

\begin{tabular}{|c|c|c|c|c|c|}
\hline \multirow{2}{*}{ Grand Mal } & \multirow{2}{*}{$\begin{array}{c}\text { Temporal } \\
\text { Lobe }\end{array}$} & \multicolumn{2}{|c|}{ Jacksonian } & \multirow{2}{*}{ Mixed } & \multirow{2}{*}{$\begin{array}{c}\text { Not } \\
\text { Classified }\end{array}$} \\
\hline & & Motor & Sensory & & \\
\hline 29 & 6 & 4 & 3 & 6 & 5 \\
\hline
\end{tabular}

3. Electroencephalography (E.E.G.).-This was performed on nine of the epileptics, and the majority had focal abnormalities, sometimes with phase reversal. These abnormalities persisted for longer than is usual with cases of uncomplicated subarachnoid haemorrhage (Rose, 1964).

4. Use of Anticonvulsants.-At the time of the first fit 41 of the 53 cases were not taking any medication. Seven of these had been on treatment but had stopped taking their drugs; 12 had been taking phenobarbitone, $30 \mathrm{mg}$. twice daily, and one of these had up to $60 \mathrm{mg}$. twice daily, but they had still developed epilepsy. These cases were all controlled when the dose of phenobarbitone was increased or phenytoin, $100 \mathrm{mg}$. b.d., was added. In no case have the fit or fits been severe enough to require either prolonged stay in hospital or gross limitation of normal activities. Of the 53 epileptics, 44 had fewer than three attacks, indicating that this type of epilepsy is not severe and responds well to treatment. In five patients who had frequent attacks, four were irregular in taking their medication, and in the four other cases information about the number of fits was incomplete. Only one patient, who refused to take the recommended medication, continued to have attacks.

\section{Discussion}

The true incidence of epilepsy after a ruptured intracranial aneurysm is higher than the $10 \%$ found in the retrospective survey for three reasons: first, when a smaller sample was seen personally and reliance was not placed solely on case records the incidence was found to be nearly $15 \%$; secondly, the cases admitted during 1962 have been followed up for less than two years, and some of these, we have shown, are likely to develop fits; and, thirdly, patients treated operatively have been routinely prescribed anticonvulsants. All these factors would tend to diminish the true epilepsy rate.

There are surprisingly few reports on the association of epilepsy and cerebrovascular disease. Walton (1953) found 15 epileptics in 120 survivors of a series of subarachnoid haemorrhage cases, an incidence of $12.5 \%$. Two of the epileptics had angiomatous malformations, and as some of his other cases did not have arteriography the diagnosis of intracranial aneurysm was not always confirmed. In his series the attacks almost invariably developed between four months and one year after the bleed, and E.E.G. studies suggested focal cerebral damage as the cause.

The importance of cerebral infarction in the genesis of epilepsy has been studied after cerebrovascular accidents (Richardson and Dodge, 1954), but this series excluded cases of intracranial aneurysm. Cerebral infarction and haemorrhage were confirmed at post-mortem examination of 104 patients ; 13 of these had had fits during life and in these cases the cerebral cortex was infarcted, older lesions being associated with recurrent attacks. In fatal cases of intracranial aneurysm. approximately $75 \%$ have cerebral infarction involving the cortex (Tomlinson, 1959 ; Crompton, 1963). Most fatal cases succumb within the first month of the bleed, and it is likely that those with ischaemic cortical lesions who survive are prone to epilepsy. Because of the difficulties in diagnosing cerebral infarction in life it is impossible to be certain how many survivors of ruptured intracranial aneurysm have suffered this complication.

Epilepsy in our series was particularly associated with an intracerebral haematoma, and reflects the greater brain damage produced with this complication. Comparison was made with a series of cases of primary intracerebral haematoma studied to find out the epilepsy rate; these were admitted during the second half of 1960 to the neurosurgical unit, and of the 47 patients so diagnosed 23 survived for two years or more and 4 $(17 \%)$ developed fits. These numbers are, of course, much too small for definite conclusions, but the incidence is similar to that found after ruptured intracranial aneurysm and emphasizes the importance of an intracerebral haematoma in the production of epilepsy after a ruptured aneurysm. That the fits are associated with brain damage is evidenced by the higher incidence of residual signs in the epileptic group than in the non-epileptics. The significance of brain injury in the production of epilepsy after rupture of an intracranial aneurysm can be compared with the figures given for post-traumatic epilepsy ; in blunt head injury the epilepsy rate is about $5 \%$. if there is associated blood-stained cerebrospinal fluid the incidence is doubled, and if there is an associated haematoma it is quadrupled (Jennett, 1962). When fits occur they start in $80 \%$ of the cases within two years of the injury (Caveness and Liss, 1961 ; Evans, 1962), which is similar to the time of onset in the present series. Neither convulsion nor coma at the onset of the bleed seems to have significance in predicting whether epilepsy will subsequently occur. This may seem to contrast with post-traumatic epilepsy, where early fits predispose to further attacks. An analysis of the timing of the fits in that condition (Jennett, 1962) shows that if the attacks occur immediately after the trauma the incidence of further fits is no greater than if the attacks had not occurred.

The part played by operation is difficult to assess, as the frequency of epilepsy will depend on whether the lesion for which craniotomy is undertaken is epileptogenic. In a series of 260 hypophysectomies for pituitary neoplasm, a lesion which rarely produces epilepsy, 10 patients developed fits, but seven of these had evidence of brain involvement by tumour (S. G. Elkington, personal communication, 1964). This suggests that 
craniotomy per se is of little importance in the development of post-operative epilepsy.

Cases of middle cerebral aneurysm are more common in the epileptic group, as would be expected in view of the distribution of the middle cerebral artery to the fronto-parietal regions and the frequent development of a haematoma in the temporal lobe or the sylvian fissure. This is comparable to the higher incidence of post-traumatic epilepsy when the fronto-parietal areas are involved (Caveness and Liss, 1961). The patients with epilepsy in this series are younger than the average age for the whole group, but this is explained partly by a loading of cases of middle cerebral aneurysm in the younger age-groups.

Fits following subarachnoid haemorrhage are usually generalized, but any type may occur. At the time of the first fit $80 \%$ of the epileptics were not taking anticonvulsants, and the remainder were taking only minimal dosage. Five patients had their first fit more than 18 months after the original illness, and three of these after more than two years. Anticonvulsant therapy should therefore be continued for at least two years, and for those at risk three years. The fits were easily controlled with anticonvulsant therapy; relapses were rare once the patients took the drugs, and, apart from an initial mild midday drowsiness, there were no side-effects from the treatment. Phenobarbitone, $30 \mathrm{mg}$. b.d., is usually sufficient to prevent the attacks; if this dose is inadequate it can be raised to $30 \mathrm{mg}$. t.d.s., and if necessary phenytoin, $100 \mathrm{mg}$. daily t.d.s., may be added.

\section{Summary}

A total of 1,009 cases of ruptured intracranial aneurysm have been studied ; epileptic attacks occurred in $53(10.4 \%)$ of the 508 survivors. The incidence was $14.8 \%$ when a small sample was examined personally.

Fits were more likely to occur in the younger age-group, when the aneurysm was situated on the middle cerebral artery, and in the presence of an intracerebral haematoma. Patients with residual signs of brain damage seemed to be particularly at risk. The fits were usually of the grand-mal type, but focal or temporal-lobe epilepsy also occurred, and different types of fit were occasionally seen in the same patient. Five patients had their first fit more than 18 months after the aneurysm had ruptured.

At the time of the first fit $80 \%$ of the epileptics were not taking anticonvulsants. In most cases the fits were few in number and were well controlled with anticonvulsant therapy. Phenobarbitone, $30 \mathrm{mg}$. b.d., should be given routinely for two years after all cases of ruptured intracranial aneurysm. In cases particularly at risk-for example, younger patients with a ruptured middle cerebral aneurysm associated with an intracerebral haematoma or evidence of residual brain damagethe dose should be increased to $30 \mathrm{mg}$. t.d.s. and continued for three years. If the patient has an attack, phenytoin, $100 \mathrm{mg}$. once to thrice daily, should be added.

We wish to thank Messrs. W. McKissock, L. S. Walsh, and A. E. Richardson for permission to study the patients admitted under their care. We are grateful to Dr. Martin Gardner, of the Social Medicine Research Unit (M.R.C.), for his help in the statistical analysis. The expenses for this work were defrayed by the Wolfson Foundation (F.C.R.) and the National Institutes of Health, Bethesda (M.S.).

\section{REFERENCES}

Caveness, W. F., and Liss, H. R. (1961). Epilepsia (Amst.), 2, 123. Crompton, M. R. (1963). Brain, 86, 30i.

Evans, J. H. (1962). Neurology (Minneap.), 12, 665.

Jennett, W. B. (1962). Epilepsy after Blunt Head Injuries. Heinemann, London.

McKissock, W., Richardson, A., and Walsh, L. (1960). Lancet, 1, 1203.

Richardson, E. P., and Dodge, P. R. (1954). Epilepsia (Amst.), 3, 49.

Richardson, E. P., and Dodge, P. R. (1954).

Rose, F. C. (1964). Rev. Neurol. In press.
Tomlinson, B. E. (1959). f. clin. Path., 12, 391.

Walton, J. N. (1953). Electroenceph. clin. Neurophysiol., 5, 41.
- Assistant Psychiatrist, Prince Henry's Hospital, Melbourne ; formerly Research Fellow in the Department of Child Psychiatry, Guy's Hospital, London. contractures characterized by vasomotor, secretory, and trophic changes are "reflex" and organic in origin, and therefore inaccessible to psychotherapeutic management (Babinski and Froment, 1918). There is, however, adequate evidence that such changes do occur in "hysterical" contracture (Brodie, 1837 ; Briquet, 1859 ; Charcot, 1890), that they are often reversible (Steindler, 1935; Hurst, 1941), and that they are eminently accessible to psychiatric management (Fraser, 1919 ; Macalpine and Ross, 1956).

In this article some characteristics of hysterical contractures in children are described and an approach to their psychiatric management based in part on the principles of learning is discussed.

\section{Clinical Picture}

Six cases of hysterical contracture have been seen in the department of child psychiatry, Guy's Hospital, during the past five years. In three the non-dominant hand was involved. When first seen, the fingers were tightly clenched and initially resistant to even minimal attempts at passive movement. In 